\title{
Educational uses of Cartography. An example on the use of GIS to deal with depopulation by skill processes
}

\author{
Velilla Gil, Javier $^{\mathrm{a}}$, Guallart Moreno, Carlos ${ }^{\mathrm{b}}$ y Laguna Marín-Yaseli, María \\ ${ }^{a}$ Chief Department of Geography and History, IES “El Portillo”, Zaragoza (Spain). jvelillagil@gmail.com \\ ${ }^{b}$ Teacher of Geography and History, school “Santa María del Pilar (Marianistas)”, Zaragoza (Spain). cquallart@gmail.com \\ c Teacher of Geography and History, school “Colegio del Salvador” (Jesuitas), Zaragoza (Spain) mlaguna@jesuitaszaragoza.es
}

\begin{abstract}
This paper analyses the use of Cartography made by Geographical Information Systems (GIS) in K 12 education levels with these two objectives:

1) Get students familiar with this type of Geographical representation.

2) Achieve that students get skill learning on Geography and Cartography.

To achieve these main objectives, the paper develops and shows some educational resources about depopulation processes in the Spanish region of Aragon. The choice of this topic is based on its cartographical possibilities and to the capacity of these processes to shape land. These educational resources are publicly and freely available to be used with students between 12 and 18 years old.

This paper begins justifying the choice of this topic and analysing the pedagogical and educational possibilities of GIS. Second, it is studied the current and past depopulation processes that took place in Aragon, along with the ways of cartographical representation commonly used in education and, the ones used to create these materials, reasoning our choice. Then, the paper describes the materials and resources and provides free downloading links. Fourth, we conclude with the evaluation of the initially proposed objectives, with a focus on the quality and advantages of the use of GIS as educational resource. The paper concludes with some future research suggestions.
\end{abstract}

Keywords: cartography, education, GIS, depopulation, Geography.

\section{Introduction}

This paper has been written in order to present educational materials that were made to analyse past and present depopulation processes in Mediterranean Europe, specifically in Aragon ("Nomenclature des Unités Territoriales Statistiques" [NUTS] 2), by dealing with a key tool such us cartography made by Geographical Information Systems (GIS).

\subsection{Depopulation significance}

Depopulation processes are a key issue in the shaping of territories, as they have modified the ways and intensity in which human societies use the space they need (García et al., 1996). In Aragon, this significance is so important (Collantes and Pinilla, 2001) because, in 2020, more than the 51 percent of the inhabitants (i.e., about 1.300 .000 individuals), lived in Zaragoza. Other important figures of Aragon are the 60 percent of the population living in four municipalities with more than 20.000 inhabitants, and the 69.4 percent living in municipalities with more than 10.000 inhabitants. That is to say, in 2020 the 69.4 percent of inhabitants of Aragon lived on the 8.8 percent of the land (with more than a half living on the 2 percent of the territory). On the contrary, there were 203 municipalities with less than 100 inhabitants, representing the 28.5 percent of the total municipalities, and the 0.95 percent of the inhabitants. These figures highlight the imbalance of the population distribution and its unsustainability.

This imbalance contrasts, among others, with two main facts:

- The commitment of most of the United Nations members in 2015, in the frame of Sustainable Development Goals of 2030 (SDGs). These goals aim at eradicating poverty, protecting the planet, and assuring prosperity as key points for sustainable development. Depopulation Processes in any part of the whole world are a sign of an imbalance distribution of wealth and of future and equal development. Moreover, they have environmental negative consequences. One of the tools implemented to reach these SDGs is the socalled Environmental Education (EE) (Kyburz Grabe, 2013). EE is oriented to educate new citizens, who need to be ready to change what is a potential risk for Earth survival and the societies who live in it.

- In spite of the economic, social and environmental relevance of these depopulation 
processes, and of the commitment to achieve sustainable development, there is no mention of these processes in the Spanish curricula of K-12 (RD 1105/2014, from December 26). EE should be the key issue in order to have these new citizens ready to act as key elements on new forms of Sustainable Development.

Thus, one of the main objectives of the resources we show in this paper is to get them into the classes and to collaborate on the development of Environmental Education.

\subsection{Cartography and skill learning}

Given that Geography is the science that analyses the land as a result of the interactions between societies and their land footprints, depopulation processes are a geographical problem, as they generate an imbalanced distribution of population in territories and an unequal ability to articulate it. In this context, Geography is the science that, using Cartography as main tool, elaborates and creates data and different measures of territories devoted to create and use maps (symbolical representation of the land), that allow us to identify the elements that form these territories.

This knowledge leads to the field of geographical analysis and makes possible to most important aim of Geography and Cartography: the resolution of problems on societies and the territories they live in. The capacity of Geography and Cartography to take action on land has its own reflect on the way both are taught and learnt. So, by using them, we have to help students to be able to identify those problems, and to understand, analyse and plan ways to solve them. This epistemological profile matches with the educational model that gets its way at the European Union based on the proposal of the European Parliament and Council on skill learning (COM, 205, 584, 10th November 2005). This proposal deals with the transition from past educational models based on contents to models based on skill learning where concepts are the scaffold to live in a responsible way.

GIS are not only the key tools in this geographical knowledge, but also educational tools in skill learning (Roig, 2010). Their educational potential relies on three key elements:

- The way in which they favour the overlapping of different layers (De Miguel et al., 2016), by: identifying the elements that shape the lands, identifying and understanding the inter-relations among them (multi-causality), and by identifying, understanding and differentiating between human and environmental elements, and evaluating the consequences of these inter-relations.

- GIS uses geospatial analysis tools, which are capable of dealing with huge amount of data to analyse, stablish inter-relations, and develop models, among others. This ability not only has a great importance in the professional use of GIS, but also on educational levels, where it allows students to deal with these geographical tasks in a simply and fast way (Kerski, 2003).

- This characteristic to analyse and represent data comes with additional ones, which include the communication of results and the storage of data. These characteristics are quite important in education at the society of information (Sinton and Lund, 2007), as not only they promote those skill learning but also favour teamwork, as they lead to collective work in a unique cartographic environment, as the "Hub" of ESRI software.

Most recent GIS are giving particular importance to this collaborative form of building knowledge, and its subsequent scientific dissemination. These new tools allow teachers to work on geographical content on an interactive way by:

- $\quad$ Pre-designed and simple apps of spatial analysis that are developed by teachers themselves and offered to the students in order to save time and effort in order to be devoted to learn Geography.

- Specific apps devoted to introduce students to particular geographical problems, and help them to analyse, understand, and solve them by using maps, images, podcasts, videos, etc. In Education, the main outcome is a process in which teachers show resources and materials, and students work on them by learning these cartographical and geographical skills (Barbas et al., 2014).

To sum up, the use of GIS as educational tools favours learning and teaching strategies based on "project based learning” (Prats and Santacana, 2011; Buzo, 2016), especially those in which students live. The understanding of these problems and the development of abilities and capacities to solve them increases students' self-stem and leads them to the use of "learning-service" strategies that facilitate learning citizenship skills and social commitment.

\section{Conceptual basis}

\subsection{Depopulation concept}

Depopulation processes are processes that lead to these two inter-related results:

- The drastic and long-run loss of population that inhabits a territory until it becomes depopulated (Collantes and Pinilla, 2011). This loss has been identified by the loss of inhabitants in municipalities at the end of 19th century, when depopulation processes started -quite slowly at the beginning but accelerating subsequently- as a process associated to urban, social and economic as part of the modernization of the Spanish Economy. Following the standard thresholds stablished by the European Commission, a population centre can be considered depopulated in three stages. 1) Under high risk of depopulation, if the population core is inhabited by 6-10 individuals. 2) Under very high risk of depopulation, if inhabited by 2-5 individuals. 3) 
Completely depopulated, if inhabited by $0-1$ individuals.

- A decrease of the human intensity on the territory (García et al. 1996), measured by land use changes (CORINE Land Cover, comparison of forestry maps, or aerial photos and orthophotos from different dates, etc., obtained from the Instituto Geográfico Nacional and the Spanish Ministry for the Ecological Transition and Demographic Challenge). These changes come from a decrease on occupied land by artificial uses, especially agricultural ones, and by an increase on natural uses. Nevertheless, this decrease of artificial use does not mean that a grade zero of human intervention on a territory is going to be reached. There are always some footprints of the past, or new uses such us rural tourism or basic communications, not related to agrarian uses that are highly dependent of land use.

To sum up, depopulated areas are those who are uninhabited (or are likely to be so in a near future), and have suffered from a great decrease in human intensity. Following these criteria, in the Aragón region, we realize that those places are located in which the European Commission (2020) calls "disadvantaged areas" and "mountain areas", characterized by being extremely wide areas, with a high concentration of depopulation process and precarious or highly deteriorated transport infrastructure (i.e., low accessibility), which prevents from human intervention from close areas (Lasanta and Errea, 2001). In the rest of rural lands who are suffering from depopulation processes, these population losses have not implied the complete abandon of human uses, although some of them are maintaining agrarian uses by extensive forms of crops (related to part time agriculture or to widening exploitations in order to compete in a globalized world), combined with livestock farming, tourism, sports, or even industrial or tertiary uses, but at same time maintaining human activity. These spaces, then, still remain as human biomes (Ellis et at., 2010). Thus, this suggests the existence of different models for depopulation processes, depending on the different causes, and the diverging effects on the territory.

This new concept on depopulation gets its way to an environmental vision of depopulation. It minimises human intervention, slows down environmental changes and, at the same time, questions the continuity of these biomes, given that it should not be expected that natural factors create, by their own, natural or savage biomes, as human ones were the result of environmental changes that took place from the last glaciation on. In other words, it should be impossible to move from human depopulated biomes to natural ones, given the changes produced by past human intervention. This places those biomes in a dramatic situation: the abandon of human activity made them more vulnerable to natural hazards just because there is not any human intervention to control them. Therefore, there is an increased risk of hazards, including forest fire, debris flow, meteorological phenomena, floods, etc.

\subsection{Depopulation and its cartographical presentation}

Until a few years ago, it was standard to represent demographic gaps in Spain by using population distribution focused on the number of inhabitants or population density by province (NUTS-3), taking as granted that lower levels of these magnitudes represented increased depopulation processed. This is the criteria used by the European Commission to define areas "sparsely populated", with these areas corresponding to NUTS-3 areas with a population density lower than 12.5 inhabitants per km2. However, this criterion would produce poorly informative maps if they aim at representing depopulation processes. First, there are several NUTS-3 areas with decreased population density for several centuries. Second, NUTS-3 based maps cannot represent where depopulation processes take place, as they essentially ignore intraprovince processes. To take but one example, in the case of the province of Zaragoza, NUTS-3 based maps cannot capture the depopulation of small villages whose inhabitants have moved to the big city of the same province (Zaragoza, which comprises mora than the 70 percent of the inhabitants of the province). That is to say, depopulation processes do not arise exclusively from interprovince movements, but also from intra-province ones, which cannot be captured using the existing standard tool to study depopulation. To tackle this issue, the European Commission has recently introduced two changes in the criteria to identify sparsely populated areas, which also affect to the way in which such areas should be cartographied:

- The criterion based on NUTS-3 regions to identify sparsely populated areas remains, but in order to address intra-province heterogeneity in the distribution of population, especially into urban and rural areas, this criterion now includes municipalities as spatial units within NUTS-3 regions, keeping the threshold of 12.5 inhabitants per km2.

- A new criterion is now considered: having had losses during the 2007-2017 period of, at least, 1 percent. This new criterion tackles the problem of "inherited depopulation", which is the lack of population due to depopulation process that took place more than a century ago, and that have resulted in a consolidated low human intervention in certain areas.

In this new context, the most common method to represent depopulation in scientific cartography is to use population density by municipality, in a choropleth map with ranges, which need to be clearly defined in terms of relevant indices, to understand the intensity of depopulation processes. This way of studying depopulation allows us to identify and locate in an accurate way depopulation processes, and then to associate them with their different potential causes. At the same time, this new representation has to face some new problems: 
- Municipal territory sizes are heterogeneous in Spain, resulting from the pool of different population cores for administrative decisions that account for historic motives, along with efficiency and homogeneity in the distribution of services and administrative competences.

- The coexistence of regions with predominance of disperse population, and regions with concentrated population, which notably affects the size of municipalities and its population density. Furthermore, in those areas characterized by disperse population and small municipalities that have suffered profound depopulation processes, there have emerged some collective aggregations as the result of associations among small population cores (e.g., "pedanías", “concejos”, etc.).

Thus, this cartographic model tries to show the intensity of depopulation processes in the different parts of the territory, but can distort the objectivity of the analysis in some areas, not allowing for a deep degree of accuracy in some depopulation processes.

From some years on, it is common to represent the distribution of the population using squared nets, of which each side has one $\mathrm{km}$ of length. For each of these squares, the number of inhabitants is represented in the map, producing a very visual figure of the distribution of the population in a territory, where the gaps in population can be easily identified. However, empty spaces do not necessarily represent depopulation processes that have occurred during the last two centuries, neither that human activity has decreased or ceased in these areas. Thus, we propose that it is necessary to cartography those areas that are depopulated, allowing then to identify where these depopulated areas are concentrated, disregarding the administrative limits in which these areas are located nowadays, to study and locate the regions in which depopulation processes have taken part.

\section{Results}

The contents are organized in Chapters, in a "hub" platform entitled "Los procesos de despoblación en Aragón”. The materials are available at: https://bit.ly/despoblacion_aragon. Each Chapter is developed as a "story" in which, using maps and additional interactive materials, the teaching-learning processes related to the corresponding Chapter are shown and developed. The topics included in every Chapter are described below.

\subsection{Depopulation on Aragon. Depopulated areas}

The contents of this Chapter are available at: https://arcg.is/1uKPLu0. It starts with an introduction to the materials and contents, and the basic instructions for the use of such materials. Then, the depopulation processes that have occurred are addressed in three ways: their location, the perception of the abandonment and ruin of the traces left by the former inhabitants (buildings, agricultural plots, etc.), and the way in which the processes were carried out. depopulation, which is complemented with testimonies of the feelings that the population that carried them out had.

\subsection{Causes}

The contents of this Chapter are available at: https://arcg.is/8irLf. The causes that originated the depopulation processes and their peculiarities are analysed. Among the causes of depopulation, we differentiate among economic causes, those related to the situation of agricultural activities, those related to the possibilities of access to basic services, and those related to the generalized perception of rural areas as a space in which obsolete and non-productive activities were developed.

\subsection{Spatial factors}

The contents of this Chapter are available at: https://arcg.is/0WObj50. Working with maps allows to identify 4 spatial factors related to depopulation: 1) The location of the territories with the highest concentrations of depopulation processes in mid-mountain areas, today considered "disadvantaged regions" or "mountain regions". 2) The impact of the construction of hydraulic infrastructures and the extension of irrigation associated with them had on the emigration of rural areas close to them, either due to the flooding of farmland, or due to the attraction of labour that the new large intensive agricultural holdings had. 3) The effects on economic development and migratory movements of poor accessibility to transport networks that connect territories and markets, and favour access to service providers. 4) The attraction by population centres in which economic modernization processes of immigrants from nearby areas or not in which these processes were not taking place were taking place.

\subsection{Depopulation models in Aragon}

The contents of this Chapter are available at: https://arcg.is/1ibb1y. This Chapter first introduces the factors that played a role in the different ways in which depopulation processes (and their consequences) took place in the different territories. For instance, the Chapter identifies seven models for these processes in terms of how depopulation affected territories:

a) Those created by the comparatively little economic profitability of agrarian activities, relative to other economic activities. This is a generalised cause in rural areas, which gives rise to continuous and long depopulation processes, which then produce two progressive processes: population decline and aging.

b) Those caused by the increasing impact of such little profitability, in addition to the articular conditions of disadvantaged or mountain areas. In this model, the population outflow, though characterised by a slow initial phase, has a highly concentrated determinant over time, which involves "demographic emptying” and a drastic reduction in human influence over the territory. 
c) Those related to the closeness to urban areas with were suffering modernization at the time, including the attraction of population from rural to urban areas, and the taking up of these individuals by urban cores in the process of modernization and growth. The rate at which these processes are carried out depends on the economic development process of the population core that is economically modernizing and attracting population, and on the rate of expansion of artificial land uses. Human influence persists in most of the depopulated territory, either due to the maintenance of agricultural uses (expansion of pre-existing farms, "part-time" agriculture, etc.), or because of the growing importance of other uses, such as those related to agriculture, transportation, services, etc.

d) Those related to the construction of dams or irrigated building. The former are usually population exit processes concentrated over time and affecting a very high percentage of the population. The latter are slower and have to do with the speed with which the development of irrigation and the modernization and intensification of agricultural holdings is carried out. The intensity of human action on the territory increases notably, but the way of doing it changes.

e) Those that took place in small villages and rural areas that were specialised in particular economic activities that become obsolete given the modernization of the economy. These are processes that are produced in a dispersed way in the territory, and have a specific impact in it. Most of them give rise to processes of substitution in the main activities that have originated these population centres by the majority in their environment.

f) Those that were the direct result of the spatial changes and increase of urban territories. These processes present two formulas: one associated with the compact growth of cities, which leads to the disappearance of previous land uses and the absorption of the population that carried them out, and another which is the result of the diffuse growth of cities, which results in the maintenance of agrarian land uses and the territorial morphology associated with them, although forming a mosaic with urban artificial uses.

\subsection{Demographic consequences}

The contents of this Chapter are available at: https://arcg.is/0GeT8a. This Chapter shows the demographic analysis of the territory of Aragón, identifying the situations that occur in unpopulated areas. To identify potential anomalies, Aragon is compared with other Spanish regions. This analysis focuses on four issues and the relationships that exist between them: the growth or decline in the number of inhabitants, migration processes, demographic aging, and the structure of the population.

\subsection{Depopulation and Environment}

The contents of this Chapter are available at: https://arcg.is/11buGa. The Chapter studies the modifications that human settlements have made to the physical environment, focusing on the impact on vegetation, relief and soils. Then, it is analysed and verified the impact that depopulation has had on the environmental quality (Net Ecological Potential, biodiversity, etc.), environmental risks (exemplified in forest fires), and vegetation. It is remarked that a direct link between depopulation and increased environmental quality is not observed. Oppositely, we show an increase in the vulnerability to dangers associated to the processes of substitution of the old vegetation by another of transition towards a wilder state (scrub, etc.), influenced by agriculture, with the abandonment of terraced slopes, etc., and also by the absence of human action to face these dangers. The Chapter concludes analysing the potential environmental improvement associated to some practices related to depopulation, such as the so called "re-wild living”.

\section{7. "España vaciada"}

The contents of this Chapter are available at: https://arcg.is/5ieLf. This Chapter is based and comprises the recent initiatives and perceptions that have emerged in Spain during the recent years, which are favourable to the repopulation of the rural world, and to the development of a current of critical opinion with the situation of abandonment of much of it. The Chapter also addresses the initiatives that are emerging from that rural world to transform it, proposing concepts such as training, empowerment, entrepreneurship, etc., and the importance of them to face depopulation processes and their consequences. The Chapter concludes describing the lifestyle in rural areas before the depopulation process from rural areas to urban areas, and tackles the initiatives that are arising in rural regions to adapt and transform themselves.

\subsection{To know more}

The contents of this Chapter are available at: https://arcg.is/n0GiD0. This Chapter includes additional resources to deep deeper into some concepts previously dealt with.

\section{Results evaluation and future actions}

Once these materials and resources have been presented, we evaluate the extent in which objectives may have been achieved:

a) The use of the resources requires the understanding of most part of the contents and tools of Geography, with the objective of the use of these materials in Education not decreasing geographical learning, but to contextualize such learning into the new regional reality of the area in which the materials are used. Those skills are 
related to the so-called Education for a Sustainable Development (Boulahrouz, 2018)

b) The format and organization of these materials is presented to focus on the process of "learning by doing”, so the students learn the theory and the concepts they need to solve current questions on territory, demography and social issues. These resources use GIS tools to solve these problems, but are not focused on the learning of GIS strategies but on their use to tackle geographic questions and problems. At the beginning of or during each Chapter and lesson, the focus is set on the understanding of the geographic issues and not on the materials used.

c) At the initial stages of this Project, the evaluation criteria were based on goals and improvements that could arise from experimentation in classrooms using the proposed materials during the 2020 and 2021. However, the pandemic situation caused by the COVID-19 disease has prevented us from stablishing such evaluation methods, as the sample of students and the working conditions were not adequate. As a consequence, the evaluation of students is pending for the next academic course.

In summary, the results found in this study include teaching materials that satisfy the main objectives. Nevertheless, there are some limitations that are left for future work, including:

- Do an exhaustive, objective and concluding evaluation of the proposed materials.

- Widen the analysed territory, moving from Aragon to closed territories such as Navarra, La Rioja, and Castilian provinces on the Iberic mountain system, Valencia, and Cataluña. Depopulation processes have been important not only in Aragon, but also in these other areas.

- Keep on spreading these resources and materials, beyond academic meetings or publications, bringing it to high-schools and teachers of secondary education (e.g., for students from 12 to 18 years old).

\section{References}

Barbas Coslado, A., Goig Martínez, M., López-Jurado Puig, M., Román González, M., Santiago Campión, R., Santoveña Casal, S., Tasende Maña, B. y Trillo Miravalles, M.P. (2014). La educación en la sociedad del conocimiento. En M. Goig Martínez (director), Formación del profesorado en la sociedad digital. Investigación, innovación y recursos didácticos. UNED.

Boulahrouz Lahmidi, M. (2018) Aprendizaje móvil y ciudadanía espacial en la educación para el desarrollo sostenible. Una propuesta para enseñanza de las ciencias sociales en educación secundaria obligatoria [Tesis doctoral, Universidad de Girona]. E-Archivo: http://hdl.handle.net/10803/620791

Buzo, I. (2016). Aplicación de la Metodología del Aprendizaje Geográfico por descubrimiento basado en
SIG en proyectos didácticos para $2^{\circ}$ de Bachillerato. En Sebastiá Alcaraz, R y Tonda Monllor, E.M, (eds.): La investigación e innovación en la enseñanza de la Geografía. San Vicente de Raspeig, Universidad de Alicante, pp.477-489

Collantes, F. y Pinilla, V. (2011). Peaceful Surrender. The Depopulation of Rural Spain in the Twentieth Century. Cambridge Scholars Publishing.

De Miguel, R., De Lázaro, M.L., Velilla, J., Buzo, I., y Guallart, C., (2016). Atlas Digital Escolar: Internet, Geografía y Educación. Ar@acne. Revista electrónica de recursos en Internet sobre Geografía y Ciencias Sociales. Barcelona: Universitat de Barcelona, $\mathrm{n}^{\circ}$ 212, 1 de septiembre de 2016. Recuperado el 17/11/2019 en http://www.ub.edu/geocrit/aracne/aracne-212.pdf

European Commission. (2020). New Cohesion Policy. https://ec.europa.eu/regional_policy/en/2021_2027/

García, J.M., Lasanta, T., Ruiz, P., Ortigosa, L., White, S., González, C., y Martí, C. (1996). Land use changes and sustainable development in mountain areas: A case study in the Spain Pyrenees. Landscape Ecology 11(5), pp.267277.

Ellis, E. C., Goldewijk, K., Siebert, S., Lightman, D, y Ramankutty, N. (2010). Anthropogenic transformation of the biomes, 1700 to 2000. Global Ecology and Biogeography 19(5), pp. 589-606.

Kerski, J.J. (2003). The implementation and Effectiveness of Geographic Information Systems Technology and Methods in Secondary Education. Journal of Geography, 102, pp. 128-137. National Council for Geographic Education.

Kyburz-Graber, R. (2013) Socioecological Approaches to Environmental Education and Research. En R.B. Stevenson, M. Brody, J. Dillon y A.E.J. Wals. (eds.), International Handbook of Research on Environmental Education. Routledge. https://www.routledgehandbooks.com/doi/10.4324/9780 203813331.ch3

Lasanta, T. y Errea, M.P. (2001). Despoblación y marginación en la Sierra riojana. Logroño, Instituto de Estudios Riojanos.

Prats, J. y Santacana, J. (2011) Por qué y para qué enseñar historia. En J. Prats (coord.) Didáctica de la Geografía y la Historia, pp.13-29. Ministerio de Educación, Cultura y Deporte, Secretaría General Técnica.

Real Decreto 1105/2014, of December 26, which establishes the basic curriculum for Obligatory Secondary Education and High School, Ministry of Education, Culture and Sports, BOE No. 3, p. 307. https://educa.aragon.es/documents/20126/521996/1+Re al+Decreto+Curriculo.pdf/a051ddb9-e121-3f90-4060f23512541334?t=1578923056053

Roig-Vila, R. (2010) Innovación educativa e integración de las TIC. Un tándem necesario en la sociedad de la información. En R. Roig-Vila, y M. Fiorucci (coord.), Claves para la investigación en innovación y calidad 
educativas. La integración de las Tecnologías de la Información y la Comunicación y la Interculturalidad en las aulas. Marfil.

Sinton, D.S. y Lund, J.J. (2007). Understanding place: GIS and Mapping across the curriculum. ESRI. Inc. 